\title{
MENGANALISA DAMPAK MEA \\ TERHADAP TENAGA KERJA DALAM NEGERI DI INDONSIA
}

\author{
Oleh: \\ *)Aisyah Amalia \\ **) Dosen Tetap IAIN Salatiga \\ amaliaaisyah3@gmail.com
}

\begin{abstract}
Abstrak
Sejak disepakatinya pembentukan Masyarakat Ekonomi ASEAN (MEA) pada tahun 2015, negara-negara kawasan Asia Tenggara telah mempersiapkan negaranya untuk menghadapi MEA. MEA merupakan pasar bebas antar negara-negara di kawasan Asia Tenggara. MEA dapat membawa pengaruguh positif apabila negara dapat mengambil peluang dan manfaatnya. Dari adanya MEA membantu merangsang perekonomian karena adanya kemudahan untuk memperjual belikan barang dan jasa serta mempermudah keluar masuknya tenaga kerja dari satu negara ke negara lain. MEA menjadi berdampak negatif ketika suatu negara belum siap menghadapinya dan tenaga kerja dalam negeri dapat terancam. Untuk mengatasi hal itu pemerintah melakukan berbagai upaya guna meningkatkan kualitas sumber daya manusia Indonesia, hal pokok yang harus diperhatikan dalam meningkatkan kualitas tenaga kerja dalam negeri adalah sektor kesehatan, sektor pendidikan, komunikasi dan teknologi. Metode yang digunakan dalam penelitian ini adalah metode kualitatif deskriptif yang mendeskripsikan tentang berbagai dampak serta hal yang perlu dipersiapkan dari adanya MEA.
\end{abstract}

Kata Kunci : MEA, Tenaga Kerja, Indonesia

\section{Pendahuluan}

Dewasa ini perekonomian dunia menunjukkan perkembangan yang meningkat. Dalam era globalisasi seperti saat ini hampir tidak ada batasan antara satu negara dengan negara lain. Globalisasi telah membuat dunia terintegrasi dalam satu kawasan perdagangan karena kemajuan ilmu pengetahuan dan teknologi serta kemajuan teknologi informasi (Christofora,2014:483). Arus globalisasi yang pesat ini dapat membawa pengaruh yang positif serta negatif bagi masing-masing negara. Pengaruh globalisasi tidak hanya berpengaruh terhadap sosial budaya, melainkan juga berpengaruh terhdap sektor perekonomian bangsa. Banyak negara-negara yang berada dalam satu kawasan membentuk asosiasi perdagangan. Indonesia salah satunya yang menjadi anggota pasar bebas dunia. Pasar bebas ini merupakan keadaan dimana terdapat kemudahan bagi antar negara untuk melakukan perdagangan barang maupun jasa.Melalui AEC 2015, produk dan tenaga kerja asing menjadi lebih fleksibel masuk ke tiap negara ASEAN (Irfan, Dwi,2016: 142). 
Bagi negara yang termasuk dalam kategori negara maju,pasar bebas ini dapat menjadi peluang bagi negaranya. Hal ini dikarenakan pada negara-negara maju telah siap untuk bersaing dengan negara lain, pasalnya sumber daya manusia di negara maju mayoritas memiliki kualitasyang baik dibandingkan dengan sumber daya manusia di negara berkembang. Sebaliknya, bagi negara-negara yang belum siap dalam menghadapi pasar bebas ini, hal ini dapat menjadi tantangan yang tidak bisa dihindari. Setiap negara harus mempersiapkan dalam persaingan pasar bebas yang akan dilalui agar tidak hanya menjadi penonton dan batu loncatan keberhasilan negara maju. Berbagai usaha telah dilakukan oleh pemerintah guna memenangkan perdagangan di pasar bebas.

Banyak sektor-sektor yang perlu dipersiapkan dalam menghadapi pasar bebas ini, salah satunya adalah kesiapan sumber daya manusia di suatu negara. Persiapan sumber daya manusia dapat dilakukan dengan meningkatkan kualitas pendidikan warga negara, kesehatan masyarakat serta lingkungan hidup dan terus mengasah skill masyarakat baik softskill maupun hardskill(Erliz, Rifa, 2013:2). Mempersiapkan sumber daya manusia merupakan hal yang snagat penting dalam menghadapi pasar bebas karena dalam pasar ini akan banyak tenaga kerja asing yang masuk ke dalam negeri serta tenaga dalam negeri yang akan bekerja di luar negeri. Dikhawatirkan bahwa dengan masuknya tenaga asing ini dapat berakibat buruk terhadap keadaan tenaga kerja dalam negeri. Mengingat tingginya kualitas tenaga asing dibandingkan Indonesia.

Banyaknya peningkatan pertumbuhan penduduk Indonesia tentunya akan bertambah pula jumlahangkatan kerja di Indonesia. Maka dari itu negara harus menyediakan lapangan pekerjaanyang besar pula untuk memenuhi kebutuhan angkatan kerja. Sayangnya di Indonesia pemerintah belum mampu untuk memenuhi kebutuhan lapangan pekerjaan untuk para angkatan kerja. Hal ini mengakibatkan adanya pengangguran yang akan terjadi di Indonesia. Pengangguran ini juga diakibatkan karena adanya krisis global beberapa saat yang lalu sehingga mengurangi produksi barang dan jasa yang akan berdampak langsung pada pengurangan tenaga kerja.

Tidak dapat dipungkiri bahwa kemajuan zaman pada saat ini juga berdampak pada perekonomian dunia. Salah satunya adalah perubahan industri dari padat karya ke industri padat modal (Erliz, Rifa, 2013:3). Perubahan ini dinilai tidak pas untuk perekonomian di Indonesia, dimana indutri padat modal hanya membutuhkan sedikit tenaga kerja sedangkan di Indonesia dengan jumlah angkatan kerja yang besar sangat membutuhkan lapangan pekerjaan 
yang banyak pula. Peralihan industri dari padat karya ke padat modal dinilai tidak menyerap banyak tenaga kerja sehingga jumlah masalah pengangguran tidak terselesaikan.

Kurangnya percaya diri dari tenaga kerja Indonesia ketika menghadapi tenaga kerja asing yang dianggap memiliki kualitas yang lebih handal, cerdas dan berkompeten membuat tenaga kerja Indonesia berkecil hati. Mental inilah yang harusnya dihilangkan tenaga kerja Indonesia untuk menghadapi MEA. Karena pemerintah telah mengupayakan berbagai cara untuk melindungi tenaga kerja dalam negeri. Salah satunya yaitu terdapapat undang-undang yang mengatur bahwa adanya beberapa profesi yang tidak dapat diisi oleh tenaga kerja asing (Stanislaus, 2016:25).

Adanya MEA yang menyebabkan mobilitas barang dan jasa seperti tanpa batas berdampak baik pula terhadap tenaga kerja. Ketika dengan mudahnya mobilitas tenaga kerja sehingga semakin luas pula lapangan pekerjaan yang ada. Sehingga tenaga kerja tidak hanya berkesempatan bekerja di dalam negeri saja namun juga di luar negeri dan tenaga kerja juga dapat memilih jenis pekerjaan yang diinginkan. Untuk hal tersebuut maka tenaga kerja Indonesia juga harus mempersiapkan kualitas dirinya agar dapat bersaing dnegan tenaga kerja lainnya baik tenaga kerja dalam negeri maupun tenaga kerja luar negeri.

\section{Metodologi Penelitian}

Metode yang digunakan dalam penelitian ini adalah metode kualitatif. Penelitian ini bertujuan untuk menjelaskan dampak dari adanya Masyarakat Ekonomi ASEAN (MEA) terhadap tenaga kerja dalam negeri serta hal-hal yang perlu dipersiapkan dalam meningkatkan kualitas sumber daya manusia Indonesia dalam menghadapi MEA. Data-data yang diambil pada penelitian ini adalah dari beberapa jurnal dan buku yang berhubungan dengan penel

\section{Pembahasan}

\section{ASEAN dan MEA}

Association of South East Asia Nations (ASEAN) merupakan organisasi regional (kawasan) yang dibentuk oleh lima negara pendiri utama di kawasan Asia Tenggara yaitu Indonesia, Malaysia, Filipina, Singapura dan Thailand dengan penandatanganan Deklarasi ASEAN atau sering juga disebut Deklarasi Bangkok oleh kelima Menteri Luar Negeri masingmasing negara tersebut pada tanggal 8 Agustus 1967 di Bangkok, Thailand (Bella,2017:2). Kemudian anggota ASEAN bertambah seiring dengan bertambah tumbuh kembangnya kemajuan pada negara-negara ASEAN. Negara-negara yang ikut bergabung dalam ASEAN 
adalah Brunei Darussalam, Vietnam, Laos, Myanmar, Kamboja dan yang terakhir adalah Timor Leste.

Negara-negara dikawasan Asia Teggara menjadi salah satu pelaku ekonomi internasional yang cukup diperhitungkan. Awalnya, pada tahun 2003, para pemimpin ASEAN sepakat bahwa masyarakat ASEAN harus dibentuk tahun 2020, namun pada tahun 2007 para pemimpin sepakat mempercepat terbentuknya MEA, yaitu pada tahun 2015 (Bella,2017:2). Dan kegiatan tersebut tentunya terdapat berbagai hambatan, tantangan serta harapan. Oleh karena itu pada tahun 1977 anggota-anggota ASEAN setuju untuk mengtegrasi negaranya dalam bidang ekonomi bernama Preferential Trading Agreement (PTA). Kemudian pada tahun 1992 PTA dikembangkan lagi menjadi ASEAN Free Trade Area (AFTA) dan sejak tahun 2015 samai sekarang AFTA telah berubah menjadi Masyarakat Ekonomi ASEAN (MEA) atau ASEAN Economic Community (AEC). MEA sendiri memiliki empat pilar sebagai penopang integrasi ekonomi kawasan yaitu (i) pasar tunggal dan basis produksi, (ii) kawasan perekonomian yang kompetitif, (iii) pembangunan ekonomi yang merata, dan (iv) integrasi kedalam perekonomian global(Stanislaus,2016:16).

\section{Dampak MEA}

Sejak dimulainya AEC tahun 2015 bagi setiap negara yang berada didalam kawasan ini menjadi mendapatkan tantangan sekaligus peluang bagi perekonomian negara kawasan ASEAN dan Indonesia pada khususnya. AEC sendiri merupakan kerja sama antar negaranegara anggota ASEAN dalam mewujudkan ekonomi yang stabil di wilayah Asia Tenggara dan mendorong daya saing negara didalamnya agar dapat bersaing pada pasar global. Secara garis besar, persatuan pasar di antara negara-negara anggota ASEAN ini serupa dengan konsep Uni Eropa, hanya berbeda pada kebijakan moneternya, seperti kebijakan dalam mata uang(Bella,2017). Karena MEA dijadikan sebagai wilayah kesatuan pasar dan basis produksi maka akan ada arus barang, jasa, investasi dan modal yang tidak ada batasan bagi negaranegara ini.

Indonesia dengan jumlah penduduk terbesar merupakan potensi bagi perusahaan untuk memasarkan produk dan jasanya, serta potensi pasar tenaga kerja yang melimpah dapat menjadi dampak yang positif dari adanya MEA. Investasi dalam negeri berpotensi akan meningkat yang akan menambah jumlah lapangan kerja dalam negeri. Bertambahnya lapangan kerja di Indonesia dapat m,enambah kesempatan kerja bagi tenaga kerja Indonesia. Dampak 
positif lainnya adalah penduduk Indonesia dapat mencari pekerjaan di luar negeri dengan aturan yang lebih mudah (Erliz, Rifa, 2015:2).

Di Indonesia sendiri terdapat pengaruh positif dan negatif dari adanya pasar bebas. Dampak positifnya kita dapat berdagang dengan mudah keluar negeri sehingga dapat menambah devisa negara serta memberi kemudahan bagi pengekspor barang ke luar negeri. Dengan adanya pasar bebas ini dapat menjadi pemacu bagi pengusaha dan perusahaan untuk memproduksi yang lebih banyak. Dengan adanya perluasan pasar ini, dapat menambah modal dari luar negeri ke Indonesia. Di era yang seperti tidak ada batasnya ini dimana ilmu dapat kita peroleh dimana saja dan kapan saja sehingga memotivasi masyarakat untuk lebih berinovasi dan berkreasi agar menunjang pertumbuhan ekonomi negara.

Sedangkan dampak negatifnya adalah ketika Indonesia belum siap dalam pasar bebas ini mengakibatkan Indonesia kalah dalam persiangan. Apabila produk dalam negeri tidak dapat bersaing dengan produk luar negeri, maka tenaga kerja Indonesia juga akan terancam (Chirstofora,2014:485). Ketika produk dalam negeri kalah saing oleh produk luar negeri mengakibatkan berkurangnya produktifitas dalam negeri. Hal ini dapat mengakibatkan terancam terkena PHK tenaga kerja dalam negeri karena produktifitas berkurang.

\section{Persiapan Negara}

Mudahnya masyarakat mendapatkan informasi dapat menimbulkan dampak pada berbagai bidang. Bidang yang paling terkena dampaknya adalah bidang sosial budaya, bidang perekonomian juga terkena dampak dari globalisasi ini. Ketika ekonomi terkena dampak globalisasi maka juga akan mempengaruhu bidang atau sektor lain, ketenaga kerjaan misalnya. Seperti yang disampaikan oleh Dirjen Pembinaan dan Penempatan Tenaga Kerja Kemenakertrans RI Reyna Usman saat membacakan sambutan Menakertrans Muhaimin Iskandar di acara UI Career \& Scholarship Expo XV 2013.”Suatu negara tidak dapat begitu saja menolak masuknya tenaga kerja asing apabila telah masuk dalam aturan perdagangan dunia, yang telah disepakati secara bilateral maupun multilateral,"(Erliz,2013:5).

Hal-hal yang harus dipersiapkan untuk menghadapi globalisasi adalah sebagai berikut :

a. Pendidikan

Kaitannya dengan tenaga ketika pendidikan dari tenaga kerja semakin tinggi maka kesempatan kerja juga semakin besar(Erliz,2013:6). Sedangkan seseorang yang berpendidikan akan lebih diperhitungkan di dunia kerja. Pendidikan juga dianggap sebagai akreditasi seseorang ketika mencarilapangan pekerjaan. 
Pendidikan tidak melulu tentang pendidikan formal saja, melainkan juga pendidikan informal serta ketrampilan. Sebaiknya pendidikan yang ditekuni adalah pendidikan yang memang dekat dengan dunia kerja sehingga manfaat dari ilmu tersebut terasa.

Berikut merupakan tabel angkatan kerja berdasarkan jenjang pendidikan :

Tabel 1. Angkatan Kerja Berdasarkan Jenjang Pendidikan

\begin{tabular}{|l|c|c|}
\hline Jenjang Pendidikan & Jumlah Angkatan Kerja (juta) & Jumlah Dalam Persen \\
\hline SD & 56,66 & 44,16 \\
\hline SMP & 23,12 & 18,02 \\
\hline SMA & 21,57 & 16,81 \\
\hline SMK & 12,97 & 10,11 \\
\hline Diploma I/II/III & 3,39 & 2,65 \\
\hline Universitas & 10,59 & 8,25 \\
\hline
\end{tabular}

Sumber : BPS, Berita Resmi Statistik Mei 2015, Diolah Pusdatinker

Dalam upaya meningkatkan jumlah tenaga kerjayang trampil kawasan, para anggota ASEAN melakukan kerjasama dalam bidang pendidikan. ASEAN University Network (AUN) dibentuk pada November 1995 berdsasarkan the AUN Charter, telah melakukan berbagai aktivitas di bidang akademis seperti diskusi, workshop, seminar studi, dan penelitian bersama dibidang-bidang yang menjadi prioritas ASEAN, program beasiswa, pertukaran mahasiswa, dan sebagainya(Bella,2017:8).

b. Kesehatan

Kesehatan merupakan sesuatu yang mendasar dalam pembangunan SDM, karena bermula dari jiwa dan raga yang sehat menyebabkan tingkat produktifitas meningkat. Meningkatkan kualitas kesehatan dapat dilakukandengan cara memberi pendidikan kepada masyarakta tebntang pola hidup yang sehat, menggalakkan aksi hidup sehat, memberikan subsidi kesehatan dan lain-lain.

c. Teknologi

Di era globalisasi, teknologi merupakan teman keseharian manusia. Sehingga untuk dapat bersaig, tenaga kerja harus menguasai teknologi mengingat segala aspek kehidupan saat ini memerlukan teknologi. Perkembangan teknologi jauh lebih cepat dibandingkan dengan tingkat kemahiran seseorang pada suatu teknologi teknologi pada jangka waktu tertentu(Erliz, Rifa, 2015:6). Oleh karena itu tenaga kerja Indonesia harus sering mengupdate teknologi terkini sehingga daya saing mereka juga akan meningkat. Sehingga perlua adanya pelatihan bagi pekerja 
Indonesia untuk belajar memehami tekonologi karena akan mebningkatkan daya saing mereka dengan tenaga kerja dari luar negeri.

d. Komunikasi

Komunikasi merupakan hal yang pentimg bagi kehidupan. Karena apapun akan dimulai dengan komunikasi. Komunikasi yang baik akan membawa dampak yang baik kedepannya pula. Dengan komunikasi yang baik kita dapat menambah jaringan dan relasi yang luas. Agar dapat bekerjasama dengan individu yang berasal dari berbagai latar belakang yang berbeda, maka individu harus selalu siap dengan adanya perbedaan budaya(Erliz, Rifa, 2015:491). Untuk membangun hubungan lintas budaya diperlukan pribadi yang respek kepada semua tenaga kerja bukan hanya sesama tenaga kerja dalam negri namun juga tenaga kerja luar negeri. Karena dalam pasar bebas ini, para tenaga kerja tidak hanya akan bertemu dengan tenaga kerja dalam negeri saja namun juga dengan tenaga kerja luar negeri yang berbeda budaya serta kepribadian.

\section{Keadaan Tenaga Kerja Indonesia}

Dalam pasar bebas ini menuntut inegrasi ekonomi yang lebih luas. Bentuk kerjasama ini menuntut kualifikasi profesial yang berkualitas dan memiliki daya saing yang tinggi. Indonesia memiliki angkatan kerja terbesar di ASEAN. Pada tahun 2015 jumlah angkatan kerja Indonesia mencapai 128,30 juta jiwa (BPS, 2015). Jumlah angkatan kerja Indonesia sekitar 20\% dari total jumlah penduduk ASEAN.

Tabel 2. Perbandingan Angkatan Kerja Negara Anggota ASEAN

\begin{tabular}{|l|l|}
\hline Negara & Jumlah Angkatan Kerja \\
\hline Indonesia & 118.193 \\
\hline Vietnam & 53.246 \\
\hline Filipina & 41.022 \\
\hline Thailand & 39.398 \\
\hline Myanmar & 30.121 \\
\hline Malaysia & 13.785 \\
\hline Kamboja & 7.400 \\
\hline Singapura & 3.444 \\
\hline Laos & 3.080 \\
\hline Brunei Darussalam & 186 \\
\hline
\end{tabular}

Sumber : ILO dan ADB

Menilik tabel diatas dapat kita ketahui bahwa Indonesia memiliki tenaga kerja yang paling banyak dibandingkan dengan negara-negara lain di ASEAN. Jumlah tenaga kerja yang tinggi ini menjadikan Indonesia kuat dalam menyediakan tenaga kerja yang akan bersaing. Hal ini dapat menjadi peluang Indonesia dalam memenangkan pasar tenaga 
kerja kawasan Asia Tenggara. Hal ini juga dapat menjadi ancaman bagi anggota ASEAN lainnya yang jumlah tenanga kerjanya relatif lebih sedikit dibanding Indonesia.

Memang dampak dari MEA salah satunya adalah akan banyaknya jumlah Tenaga Kerja Asing (TNA) yang masuk ke Indonesia. Namun banyaknya jumlah TNA yang masuk ke Indonesia, namun banyaknya lebih sedikit dibandingkan dengan jumlah tenaga kerja Indonesia yang keluar ke pasar MEA lebih banyak. Tenaga kerja asing yang bekerja di Indonesia paling banyak bukan berasal dari negara-negara ASEAN melainkan berasal dari Republik Rakyat Tiongkok disusul Jepang dan India (Stanislaus,2016:21). Meskipun lebih banyak tenaga kerja Indonesia yang keluar dari pada tenaga kerja asing yang masuk ke Indonesia, namun perlu dilihat juga jabatan yang diduduki para tenaga kerja ini.

Meskipun banyak tenaga kerja asing yang akan masuk ke Indonesia dan banyak orang beranggapan bahwa tenaga kerja asing memiliki keterampilan dan kualitas yang lebih, tenaga kerja dalam negeri tidak perlu terlalu riasu. Hal ini dikarenakan pemerintah telah membuat regulasi guna melindungi perekonomian dalam negeri. Pemerintah telah membuat keputusan yaitu Keputusan Menteri Tenaga Kerja dan Transmigrasi Nomor 40 Tahun 2012 tentang jabatan-jabatan tertentu yang dilarang diduduki tenaga kerja asing sebagai upaya bentuk perlindungan dan mengantisipasi globalisasi sektor jasa atau ketenegaraan ini(Bagus:5). Namun periapan SDM juga tetap harus dilakukan karena dalam pasar bebas ini perlu adanya nilai lebih yang dimiliki tenaga kerja Indonesia yang ditawarkan kepada MEA.

Ketika negara-negara dikawasan Asia Tenggara sepakat menciptakan pasar bebas kawasan Asia Tenggara yang dinamakan dengan Masyarakat Ekonomi ASEAN atau sering disingkat (MEA) maka akan berdampak bagi negara kawasan tersebut. Dari adanya MEA diharapkan dapat merangsang pertumbuhan ekonomi serta mampu bersaing di pasar global. Guna mewujudkan tujuan tersebut setiap negara seharusnya mampu mempersiapkan negaranya agar dapat bersaing. Dalam pasar bebas ini akan terjadi rotasi pasar tenaga kerja mudahnya keluar dan masuk ke dalam negeri. Maka negara perlu menganalisis hambatan mengenai tenaga kerja dalam mengdapi MEA serta mampu segera managani hambatan tersebut. Hal ini perlu dilakukan karena mengingat MEA dapat menjadi peluang bagi Indonesia dimana jumlah penduduk yang banyak, sehingga diharapkan mampu menguasai pasar bebas. 


\section{Kesimpulan}

Negara-negara di kawasan Asia Tenggara yang beranggotakan 10 negara membentuk ASEAN. Lalu pada tahun 2003 kepala negara di wilayah ASEAN sepakat membentuk pasar tunggal di kawasan Asia Tenggara yang dinamakan MEA. MEA tentunya akan mempengaruhi perekonomian negara-negara kawasan tersebut. Karena dari adanya MEA tersebut pasar barang dan jasa akan terus bergerak dengan mudah. Pasar bebas ini mengurangi regulasi-regulasi perdagangan barang dan jasa sehingga dengan mudahnya barang serta jasa keluar masuk ke dari suatu negara di kawasan Asia Tenggara ke negara lainnya.

Pasar bebas kawasan ASEAN dapat membawa dampak positif dan negatif. Dampak positif dari pasar bebas ini adalah akan banyak modal investasi luar negeri yang masuk ke Indonesia sehingga dapat menciptakan lapangan pekerjaan dan mengurangi pengangguran, pengusaha dapat mengekspor barang dengan mudah, dan regulasi barang dan jasa dalam negeri dapat berputar dengan cepat. Dampak negatifnya adalah ketika barang dan jasa dengan mudahnya masuk ke dalam negeri dapat mengancam perekonomian dalam negeri. Dalam pasar bebas ini juga mengakibatkan mudahnya tenaga kerja keluar masuk ke Indonesia. Oleh karena hal itu pemerintah perlu menilik persiapan sumber daya manusia Indonesia. Hal-hal yang perlu diperhatiakan yaitu kesehatan masyarakat, pendidikan, teknologi serta komunikasi penduduk Indonesia agar Indonesia tidak hanya menjadi penonton keberhasilah negara tetangga dalam pasar bebas ini, namun Indonesia juga menjadi salah satu negara yang berhasil mengambil manfaat atau peluang dari MEA tersebut.

Meskipun tenaga kerja luar negeri dianggap lebih berkompeten dan berkualitas dibandingkan dengan tenaga kerja Indonesia, hlnamun hal tersebut tidak perlu terlalu dibesarbesarkan. Hal ini terjadi karena oemerintah telah membuat regulasi mengenai ketenaga kerjaan luar negeri yang akan masuk ke Indonesia. Terdapat jabatan-jabatan tertentu yang tidak dapat diduduki oleh tenaga kerja asing. Pemerintah meciptakan beberapa regulasi guna melindungi tenaga kerja dan perekonomian dalam negeri agar tidak kalah atau tergilas karena belum mampu bersaing dalam pasar bebas tersebut.

\section{Daftar Pustaka}

Beik, Irfan Syauqi dan Arsyianti, Laily Dwi. 2016. Ekonomi Pembangunan Syariah. Jakarta: Rajawali Press.

Amalia, Bella. (2017) Dampak ASEAN Economic Community (AEC) Terhadap Tenaga Kerja Indonesia Di Singapura. JOM FISIP, 4, 1-14.

Apresian, Stanislaus Risadi (2016) Arus Bebas Tenaga Kerja Dalam Era Masyarakat Ekonomi ASEAN: Ancaman bagi Indonesia?. Indonesian Perspective, 2, 15-29. 
Badan Pusat Statistik. (2015) Statistik Mobilitas Penduduk dan Tenaga Kerja. Jakarta : Badan Pusat Statistik.

Pratiwi, Erliz Nindi dan Rifa Atun Mahmudah. (2012) Peningkatan Daya Saing Tenaga Kerja Indonesia Melalui Korelasi Input Penunjang Tenaga Kerja Dalam Menghadapi MEA 2015. Economic Development Analysis Journal 2, 2, 1-7.

Prasetyo, Bagus. Menilik Kesiapan Dunia Ketenagakerjaan Indonesia Menghadapi MEA. Jurnal RechtsVinding media Pembinaan Hukum Nasional. 1-7.

Soleh, A. (2017). Masalah Ketenagakerjaan dan Pengangguran di Indonesia. Cano Ekonomos, 6(2), 83-92.

Tirtawinata, Christofora Megawati (2014) Karakter Yang Diperlukan Dunia Kerja Dalam Menghadapi Pasar Bebas ASEAN 2015. Humaniora 5, 1, 483-493.

ILO dan ADB. (2014) ASEAN Comminity 2015: Managing Integration for Better Jobs and Shared Peosperity. Thailand: ILO dan ADB. 